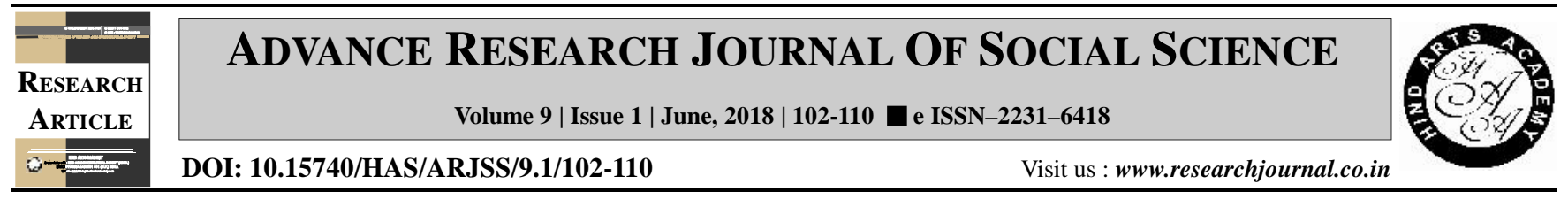

\title{
A study of relationship between religiosity and work-life balance
}

Omar Fayaz Khan* and Mohammad Sajid Kirmani ${ }^{1}$

Sher-e-Kashmir University of Agriculture, Science and Technology (K), Shalimar (J\&K) India

${ }^{1}$ IUST, Awantipora (J\&K) India

(Email: omarfayaz@gmail.com; sajidkirmani@gmail.com)

\section{ARTICLE INFO :}

$\begin{array}{lll}\text { Received } & : & 28.03 .2018 \\ \text { Revised } & : & 09.05 .2018 \\ \text { Accepted } & : & 24.05 .2018\end{array}$

\section{KEY WORDS :}

Work-life balance, Religiosity, Personal life work interference (PLWC), Work personal life interference (WPLC), Personal life work enhancement (PLWE)

\section{HOW TO CITE THIS ARTICLE :}

Khan, Omar Fayaz and Kirmani, Mohammad Sajid (2018). A study of relationship between religiosity and worklife balance. Adv. Res. J. Soc. Sci., 9 (1) : 102-110, DOI: 10.15740/HAS/ARJSS/ 9.1/102-110.

Copyright@2018 : Hind Agri -

Horticultural Society

*Author for correspondence

\begin{abstract}
Religiosity is important to frame of reference which gives directions to an individual how to face certain situations. Accordingly, issues at work and home, which take shape in the form of demands and resources provide challenge and opportunity for individuals. Religiosity gives shape to one's belief system, is a code of ethics and provides a mode of conduct regarding behaving with fellow humans. It is important to study the influence of religiosity on Work-Life Balance (WLB), ever so now as a more diversified workforce are joining the workplace. With this idea in mind, the paper seek to relate religiosity with work-life interface. 294 sample of women employees in health industry formed part of empirical study. The findings suggest that religiosity is not fully related to work-life interface, however, it does provide as means for reducing the experience of conflict. Obviously, how women approach situation in the workplace will be shaped by how religiosity plays a role in that individual's life. Very few studies have focused on this dimension while seeking to understand WLB. The paper suggests for a more intensive qualitative research studies on religiosity and WLB.
\end{abstract}

